\title{
Case Design of Linear Algebra Hybrid Teaching Model under Problem-Based Learning
}

\author{
Yanbing Yang, Qin Zhang, Bin Liu, Lidong Wang, and Xiangfei Kong
}

\begin{abstract}
Blended teaching combines the advantages of traditional classroom teaching (C-Learning) and network teaching (E-Learning), which is an important research direction of higher education teaching reform. Problem-driven teaching method is a learning party that takes students as the main body, takes various problems in the professional field as the starting point, and takes problems as the core to plan learning content so as to enable students to seek solutions around problems. In this process, teachers' roles are the problem poser, curriculum designer and outcome evaluator. In the face of the dilemma of shrinking school hours in engineering mathematics courses, we try to design a mixed teaching mode of linear algebra based on problem-driven concept in the traditional classroom teaching of linear algebra course of Engineering in universities, combining the advantages of traditional classroom and MOOC, to meet the requirements of completing the syllabus in a limited period of time. The mode design case in this paper can provide a reference for further practice and research of linear algebra hybrid teaching.
\end{abstract}

Index Terms-Flip classroom, b-learning, MOOC, problem-based learning.

\section{INTRODUCTION}

H Lars Garding, a Swedish mathematician, said in his famous book Encounter with Mathematics: "If you are not familiar with the concept of linear algebra and want to study natural science, now it seems almost illiterate."

Linear algebra was formed as an independent branch in the 20th century, but its history is very long. In fact, linear algebra in modern sense appeared in the seventeenth century because of the work of Fermat and Descartes, and it was limited to plane and space until the end of the eighteenth century. The transition to n-dimensional linear space was completed in the first half of the nineteenth century. With the deepening of the study of linear transformation of linear equations and variables, determinants and matrices came into being

Manuscript received February 20, 2019; revised July 9, 2019. This work was supported by the teaching reform project of Dalian Maritime University(No.2017Z08), and was supported in part by Liaoning Province Teaching Reform Project 2018 (Research and Exploration on Practical Teaching of Data General Education under the Background of Data Science and Technology Era).

Yanbing Yang is with the College of Science Dalian Maritime University, Dalian, China (e-mail: yyb9480@ hotmail.com).

Qin Zhang was with the College of Science Dalian Maritime University, Dalian, China (e-mail: 997247614@qq.com).

Bin Liu is with the College of Management Dalian Maritime University, Dalian, China (e-mail: liubin403881@ @otmail.com).

Lidong Wang was with the College of Science Dalian Maritime University, Dalian, China (e-mail: yang017@aliyun.com).

Xiangfei Kong was with the Shenyang Academy of Instrumentation Science Co., Ltd, Shenyang, China (e-mail: fei0810@ hotmail.com). successively during the 18 th to 19 th centuries, which provided a powerful tool for dealing with linear problems and promoted the development of linear algebra. The introduction of vector concept forms the concept of vector space. All linear problems can be discussed from the point of view of vector space. Therefore, vector space and its linear transformation, as well as the matrix theory associated with it, constitute the central content of linear algebra.

The function of algebra is to "combine" many seemingly unrelated things, that is, to abstract them. The essence of this abstraction is to classify some common problems into a class of problems and seek general solutions by generality. Linear algebra is a subject that combines geometric viewpoints with algebraic ideas. Its main research objects are vector, vector space (or linear space), linear transformation and finite dimensional linear equations. Because many practical problems can be linearized, the application of linear algebra has been deep into engineering, technology, economy, management and other fields.

For a long time, traditional classroom teaching has been adopted in our school education, that is, the teaching mode of "teacher speaking and student listening". Teachers are the main body of teaching activities, the imparter of knowledge, and students are the receivers of knowledge. Although this model has many disadvantages, its fundamental purpose is to obey the needs of subject teaching and systematically and completely impart the cultural and scientific knowledge accumulated by human society for thousands of years. Therefore, teaching mode is still adopted in most subject teaching at present. Teachers can impart basic knowledge and skills such as basic concepts, basic theories and principles to students. Through the guidance and guidance of teachers, students can acquire a large amount of knowledge quickly, centrally and systematically, and get the fastest and best development.

However, the traditional way of knowledge transfer in classroom teaching is single, which is not conducive to mobilizing students 'learning enthusiasm, depriving students of emotional life in classroom teaching, causing a dull situation in classroom teaching, and is not conducive to the development of students' innovative ability. Modern network and multimedia technology can build a friendly and lifelike learning environment for teaching, provide rich image of teaching resources, a variety of knowledge acquisition channels and diverse ways of communication between teachers and students.

At the same time, engineering mathematics courses are interlaced with each other, and the knowledge system has obvious logical relationship. However, they are facing the dilemma of less hours, heavy teaching tasks and shrinking 
hours. At present, linear algebra courses have been reduced to 40 hours (land majors) and 30 hours (sea majors). In order to fulfill the requirement of the integrity of the syllabus in a limited time, cramming teaching has become a necessary teaching method in the classroom. This kind of information-intensive, wide-ranging, fast-paced and efficient teaching mode is not conducive to the achievement of knowledge, ability and emotional goals in the personnel training plan [1]. Based on the above background, we envisage whether we can design a hybrid teaching mode based on Problem-Based Learning (PBL) by using multimedia means such as "fragmentation learning" provided by MOOC and its derivative learning resources, so as to increase students 'interest in learning, alleviate the dilemma of shrinking school hours and make up for the shortcomings of traditional classroom teaching [2].

Therefore, we intend to use the high-quality Linear Algebra Curriculum Resources of Haida Intelligence Tree Platform

( http://www.zhihuishu.com ), and try to design the mixed learning mode of linear algebra based on PBL teaching method.

\section{MiXed Teaching CHARACTERISTICS}

The concept of blended learning appeared after MOOC [3], [4]. One viewpoint holds that blended learning combines the advantages of traditional learning methods with those of e-learning. It not only plays a leading role in guiding, inspiring and monitoring the teaching process of teachers, but also fully reflects the initiative, enthusiasm and creativity of students as learning subjects. Mixed learning emphasizes the application of appropriate learning methods at the right time to achieve the best learning objectives [5].

Its essence is a kind of "online "+offline "teaching which combines the advantages of online teaching and traditional teaching. Through the organic combination of two teaching organizational forms, learners 'learning can be guided from shallow to deep learning [6]-[8]. Students can use fragmented time to study independently through network teaching platform, and integrate into traditional classroom teaching at the same time, which is helpful. Highly motivated and creative in learning [9].

\section{CONCEPT OF PBL}

\section{A. The Concept of PBL Mathematics Teaching}

The idea of PBL mathematics teaching is to create "effective problems" to drive students to actively explore and construct knowledge. Under the active guidance of teachers and the active participation of students, students are driven to learn mathematical knowledge hierarchically and develop their mathematical thinking [10].

Starting from raising questions and seeking answers, let students experience the process of occurrence and development of mathematical knowledge, understand the origin and development of knowledge, this process easily arouses students 'thirst for knowledge and activate their thinking, which can improve students' initiative in learning, perceive mathematical thinking methods, perceive and find ways to solve problems, experience and find ways to discover truth, and improving the participation of students in the Teaching Process. Participation in the process. The process of Problem-Based Learning mathematics teaching is as follows:

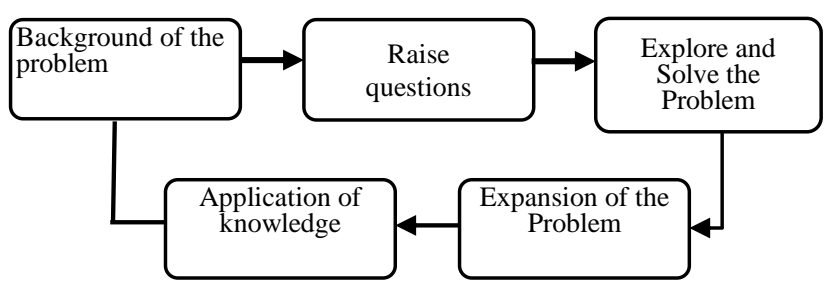

Fig. 1. The process of problem-based learning mathematics teaching.

This kind of teaching method has higher requirements for teachers. Teachers must have strong classroom control ability and guidance ability. There are not many research cases related to the course of linear algebra [11]-[15].

\section{B. Curriculum Objectives and Design Principles}

The curriculum objectives of the mixed linear algebra teaching model are shown in Table I.

TABLE I: LINEAR ALGEBRA COURSE OBJECTIVES

\begin{tabular}{|l|l|}
\hline Objective 1 & $\begin{array}{l}\text { To master the basic knowledge of linear algebra and prepare } \\
\text { for the follow-up courses. }\end{array}$ \\
\hline Objective 2 & $\begin{array}{l}\text { To guide students to learn and establish algebraic ideas and } \\
\text { methods }\end{array}$ \\
\hline Objective3 & To cultivate students 'abstract thinking ability. \\
\hline Objective4 & $\begin{array}{l}\text { To train students to use mathematical tools to analyze and } \\
\text { solve }\end{array}$ \\
\hline
\end{tabular}

The design principles of the mixed teaching mode of linear algebra course are shown in Table II.

TABLE II: PRINCIPLES OF CURRICULUM DESIGN

\begin{tabular}{|l|l|}
\hline \multicolumn{1}{c}{ TABLE II: PRINCIPLES OF CURRICULUM DESIGN } \\
\hline \multirow{5}{*}{$\begin{array}{l}\text { Design } \\
\text { principles }\end{array}$} & $\begin{array}{l}\text { With the help of geometric viewpoint and concrete } \\
\text { application, the purpose of understanding and skillful } \\
\text { application of linear algebra is gradually realized. }\end{array}$ \\
\cline { 2 - 3 } & $\begin{array}{l}\text { With linear equations and matrices and their elementary } \\
\text { transformations as the core tools, it pays attention to } \\
\text { extracting and summarizing the relevant important } \\
\text { knowledge points and typical techniques and methods. }\end{array}$ \\
\cline { 2 - 3 } & Focus on applicability and compatibility \\
\hline
\end{tabular}

\section{MODE DESIGN}

We know, vector space and its linear transformation, as well as the related matrix theory, constitute the central content of linear algebra. Vector space and its linear transformation, as well as the related matrix theory, constitute the central content of linear algebra. Next, we take the matrix and its operation module as an example, and design the hybrid learning mode of this section based on the PBL method.

\section{A. Pre-class Preparation and Problem Design}

Problem design is the basis of PBL teaching method, and whether the problem design is scientific or not is directly related to the success or failure of teaching. Generally speaking, problem design should follow the following principles. Firstly, teachers should try their best to understand the specific situation of the textbooks and students, and the problem of design must be closely centered on the teaching objective and be clear. [1]. 
Second, we should give students a clear sense of hierarchy, from easy to difficult, so as to enhance their self-confidence, stimulate students 'interest in learning, and stimulate students to think positively.

Thirdly, the problem of design should be appropriately difficult, and give students a clear sense of hierarchy, from easy to difficult, so as to enhance students' self-confidence, stimulate students' interest in learning, and stimulate students to think positively.

Fourth, the problem of design should be oriented to all students, mobilize the learning enthusiasm of each student, and strive to let everyone have the opportunity to play and perform, so that everyone can participate and everyone can gain.

Pre-class preparation and problem design are shown in Table III.

TABLE III: PRE-CLASS PREPARATION AND PROBLEM DESIGN

\begin{tabular}{|c|c|c|c|}
\hline \multicolumn{3}{|l|}{ Content } & Matrix and Its Operations \\
\hline \multicolumn{2}{|c|}{ Teaching Subject } & \multicolumn{2}{|c|}{$\begin{array}{l}\text { Sophomore of Maritime Major (Part One), } \\
\text { Linear Algebra }\end{array}$} \\
\hline \multirow[t]{3}{*}{$\begin{array}{l}\text { Pre-class } \\
\text { preparation } \\
\text { and } \\
\text { problem } \\
\text { design }\end{array}$} & \multicolumn{2}{|c|}{$\begin{array}{l}\text { Teaching } \\
\text { objectives }\end{array}$} & $\begin{array}{l}\text { 1. Understanding the concept of matrix, } \\
\text { zero matrix, diagonal matrix, unit matrix, } \\
\text { symmetric matrix and other special } \\
\text { matrices; } \\
\text { 2. Proficient in the concepts of linear } \\
\text { operation, matrix multiplication, matrix } \\
\text { transposition, determinant of square } \\
\text { matrix, adjoint matrix and its operation law. } \\
\text { 3. Understanding the concept, properties } \\
\text { and necessary and sufficient conditions of } \\
\text { invertible matrix. }\end{array}$ \\
\hline & \multicolumn{2}{|c|}{$\begin{array}{l}\text { Design } \\
\text { problem }\end{array}$} & $\begin{array}{l}\text { 1. How to define the Multiplication of } \\
\text { Matrix, Number multiplication and Adjoint } \\
\text { matrix? } \\
\text { 2. What are the operation laws of transpose } \\
\text { matrix, square matrix and determinant? } \\
\text { 3. Definition, properties and necessary and } \\
\text { sufficient conditions of reversible matrices? }\end{array}$ \\
\hline & \multicolumn{2}{|c|}{$\begin{array}{l}\text { Teaching } \\
\text { resources }\end{array}$} & $\begin{array}{l}\text { Linear Algebra Course } \\
\text { http://www.zhihuishu.com } \\
\text { extranet resources }\end{array}$ \\
\hline
\end{tabular}

*Teaching duration: 90 Minutes.

In the problem design of PBL teaching method, teachers should prepare questions before class. This step not only requires teachers to be familiar with the teaching content, but also better understand the situation of students. This is the basis of the successful implementation of problem-driven teaching method.

Teachers design the problems to be solved before class and publish them to students. Through watching video clips before class, students conduct online preview and online test exercises, most of the parts easy for students to understand and master are digested before class. In this way, teachers can focus on difficult explanation, problem expansion and knowledge application in class.

\section{B. Release Task}

Taking advantage of the short time and novelty of online resources video, we select video clips closely related to classroom topics and distribute them to students in advance as homework for pre-class preparation. This link, while stimulating students 'curiosity, can also prepare for classroom teaching, so as to improve the efficiency of curriculum learning. Pre-class preparation is shown in Table IV.
TABLE IV: PRE-CLASS PREPARATION

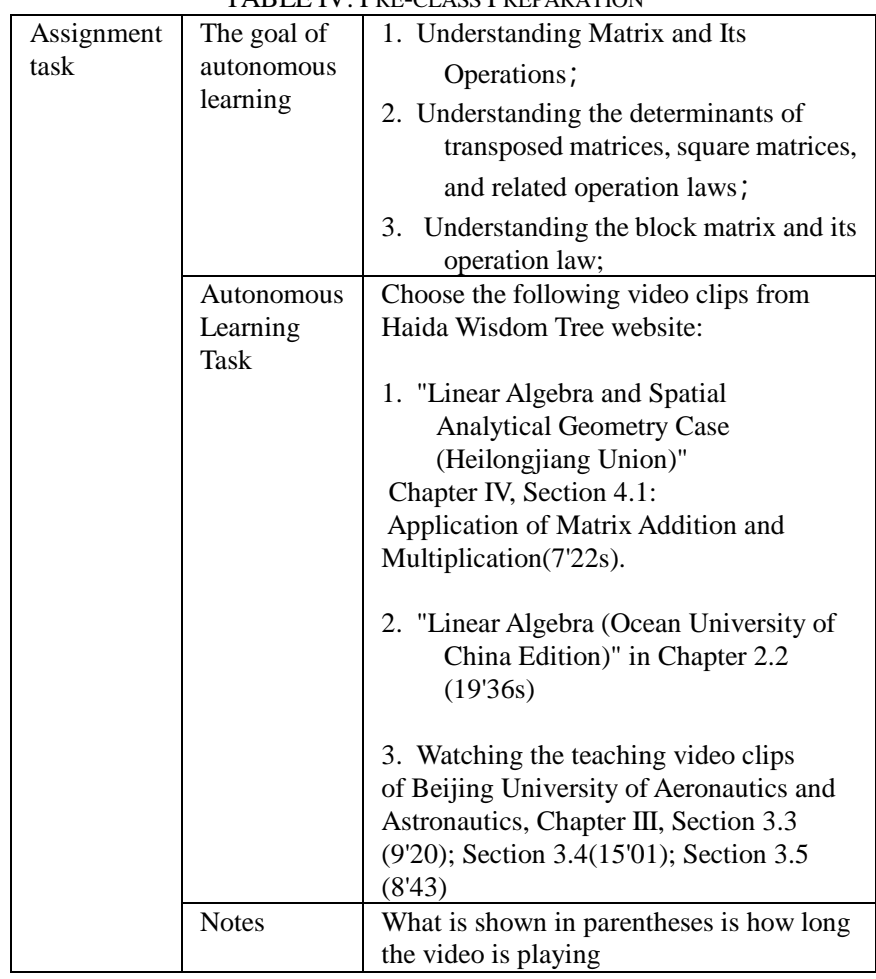

\section{Design of Classroom Teaching Link}

TABLE V: DESIGN OF CLASSROOM TEACHING LINK

\begin{tabular}{|c|c|c|}
\hline \multirow[t]{5}{*}{$\begin{array}{l}\text { Class- } \\
\text { room } \\
\text { Teaching } \\
\text { Links }\end{array}$} & $\begin{array}{l}\text { Test } \\
\text { questions }\end{array}$ & $\begin{array}{l}\text { Designing test questions according to the } \\
\text { key points and difficulties of this course } \\
\text { Time: } 5 \text { minutes }\end{array}$ \\
\hline & $\begin{array}{l}\text { Group } \\
\text { discussion } \\
\text { and } \\
\text { Result } \\
\text { analysis }\end{array}$ & $\begin{array}{l}\text { 1. Group discussion: } \\
\text { Let the students discuss and } \\
\text { communicate the test questions and } \\
\text { propose solutions to the problems. } \\
\text { 2. Result analysis: } \\
\text { According to the situation of group } \\
\text { discussion, students 'mastery of online } \\
\text { teaching content is judged, and the } \\
\text { knowledge modules and knowledge points } \\
\text { involved are explained. centrally. } \\
\text { Completion time: } 15 \text { minutes }\end{array}$ \\
\hline & $\begin{array}{l}\text { Summary } \\
\text { and } \\
\text { Explanation }\end{array}$ & $\begin{array}{l}\text { 1. Summary of the main points: for } \\
\text { relatively simple, students have } \\
\text { learned by themselves can basically } \\
\text { grasp the content; } \\
\text { 2. Key Explanations: What the students } \\
\text { can't understand and grasp after } \\
\text { self-study; }\end{array}$ \\
\hline & & $\begin{array}{l}\text { 3. Expanding problems: taking problems } \\
\text { and exercises as carriers, finding rules } \\
\text { and exploring methods; } \\
\text { Completion time: } 30 \text { minutes }\end{array}$ \\
\hline & $\begin{array}{l}\text { Comprehensi } \\
\text { ve training }\end{array}$ & $\begin{array}{l}\text { A large number of comprehensive subject } \\
\text { training } \\
\text { Completion time: } 40 \text { minutes }\end{array}$ \\
\hline
\end{tabular}

Problem analysis and problem solving are the key links of PBL teaching method. These two links of PBL are put in the result analysis, summary and explanation part of classroom teaching period. In this part, we design a hybrid teaching 
model, which includes 8 minutes of test questions, 15 minutes of result analysis, 50 minutes of summary and explanation, 17 minutes of difficult breakthrough.

In the group discussion section, let the students discuss and exchange the answers to the test questions, and put forward their own views and opinions. Teachers play a leading role in this stage. When discussing the original intention of the problem or students 'misunderstanding, they should give timely warning and guidance so that students can put forward solutions to the problem. In the result analysis part, according to the situation of group discussion, the students' mastery of online teaching content is judged, and then the related knowledge modules and knowledge points are explained centrally.

Design of Classroom Teaching Link is shown in Table V.

According to this model, after students complete the video clips before class, a large number of preparation information and basic knowledge points of the course content have been digested and absorbed by students before class, which greatly saves the classroom time. After completing the summary of key points and key explanations, teachers can also have 40 minutes to lead students to comprehensive topic training, and also make students after class. It saves time to do exercises, that is to say, students do not have to find large pieces of time to do exercises in the full schedule and the gap between various training items every day.

\section{Design of After-class Links}

In order to test the students' mastery of knowledge points in the classroom, after-class teachers test the students on the knowledge points in the classroom, and the test is divided into online and offline parts. In the online part, students return to the online classroom to complete the corresponding test questions. Teachers make corrections in the background and give the results. As part of the final examination results, this part accounts for $15 \%$ of the final results. Off-line test, teachers give students an off-line assignment of comprehensive topics after class explanation. Students need to discuss with each other and consult information to complete this part, which accounts for $10 \%$ of the final grade. This kind of teaching design can enable students to consolidate and review the knowledge they have learned, promote students to study more deeply, and lay a solid foundation for taking postgraduate mathematics exams in the future.

For example, after the learning of matrix and its operation section, teachers assign off-line homework to students, and students combine the learning of network video with classroom teacher's explanation. This process can urge students to review knowledge module carefully and deepen their understanding of knowledge points.

Design of after-class links shown in Table VI.

TABLE VI: DESIGN OF AFTER-CLASS TEACHING LINK

\begin{tabular}{|l|l|l|}
\hline Test questions & Training purpose & Completion mode \\
\hline Basic & $\begin{array}{l}\text { Examine the mastery of basic } \\
\text { knowledge } \\
\text { Time required: } 15 \text { minutes }\end{array}$ & $\begin{array}{l}\text { Complete on } \\
\text { independent line; }\end{array}$ \\
\hline $\begin{array}{l}\text { Comprehensive } \\
\text { Question }\end{array}$ & $\begin{array}{l}\text { Develop students } \\
\text { 'comprehensive ability to } \\
\text { analyze and solve problems } \\
\text { Completion time: } 25 \text { minutes }\end{array}$ & $\begin{array}{l}\text { Indepen-dent or } \\
\text { group discussion. } \\
\text { Offline } \\
\text { completion }\end{array}$ \\
\hline
\end{tabular}

\section{E. Result Evaluation}

The last step of PBL teaching method is result evaluation, including self-evaluation, group mutual evaluation and teacher evaluation, etc. The evaluation content is the rationality of problem-solving methods, personal contribution and so on. We adopt the method of combining process evaluation with result evaluation to evaluate the mixed linear algebra teaching model we designed.

Procedural evaluation includes the completion of tasks on-line, participation in discussion after class, completion of homework, mutual evaluation of homework and performance of off-line classroom. These evaluations need to be given by teachers and completed on the school's network teaching platform. The proportion of scores of each part is set through the school's network teaching platform "Statistics-Achievement Management-Weight Setting". The school network teaching platform can count the scores.

In this way, the online evaluation part of the feedback is completed immediately, and the evaluation data is convenient, accurate and detailed, which improves the reliability and validity of the test. In addition, for typical tasks, online comments can be made and corrected immediately, so that embeddedness evaluation and end evaluation complement each other, knowledge internalization and construction are unified, and the effectiveness of teaching can be enhanced.

Result evaluation still adopts the traditional teaching method of final examination. Accordingly, the total score of this course includes the sum of the corresponding scores of the process evaluation and the result evaluation, that is, the sum of the final examination results and the hourly scores. Usual results include: online test, offline test and classroom assessment results, of which, the classroom assessment results class is $5 \%$ of the total score; final examination scores 100 points, weight coefficient 0.7 , total score $=$ final examination results $* 0.7+$ ordinary results.

\section{CONCLUSION}

Based on the PBL teaching method, the linear algebraic hybrid teaching mode design case opens the matrix module, which has a lot of basic knowledge such as concept, nature and so on. A few teaching videos released in the task link of autonomous learning are vivid, interesting, short and concise. They are easy to understand and save a lot of time for teachers to occupy the classroom teaching, so that teachers have time to concise and more practice in the classroom. To expand the problems and better achieve the knowledge, ability and emotional goals in the talent training plan. Mixed teaching mode follows the modern educational concept of "learning-centered", effectively integrates technology, knowledge and methods, improves students 'knowledge and skills, and is an important way to realize the modernization of traditional classroom teaching.

The training of the implicit self-learning ability in the learning process of this mixed teaching mode not only changes the dull passive acceptance learning mode, but also helps to complete the teaching tasks stipulated in the syllabus within a limited period of time. However, compared with traditional teaching or infant in infancy, the mixed teaching 
mode has not been widely accepted, so in practice, it should be in line with the principle. The principle of combining inheritance with innovation is constantly explored, adjusted and perfected in teaching practice.

\section{CONFLICT OF INTEREST}

The authors declare no conflict of interest.

\section{AUTHOR CONTRIBUTIONS}

Yanbing Yang conducted the research; Lidong Wang, Qin Zhang and Xiangfei Kong analyzed the data; Bin Liu wrote the paper; all authors had approved the final version.

\section{REFERENCES}

[1] D. Luo, "Probe into the teaching reform practice of public mathematics Course in university under the condition of limited class hours: A case study of probability theory and mathematical statistics," Education and Teaching Forum, 2012, vol. 04, pp. 136-137.

[2] B. Li et al., "Future teaching pattern of higher education: View of evolution from OCW, MOOC to SPOC," Journal of Chengdu Normal University, vol. 33, 2018, vol. 08, pp. 12-16.

[3] B. Launer, "Five assumptions on blended learning: What is important to make blended learning a successful concept?" presented at Third International Conference, Berlin: Springer, 2010.

[4] J. K. Komarnicki and Y. F. Qian, "How do they fare? Learning achievement and satisfaction with blended learning for traditional-age undergraduates at moderately selective colleges," Information Resource Management Association. Curriculum Design and Classroom Management: Concepts, Methodologies, Tools and Application, Hershey, Pennsylvania, Global, 2015.

[5] L. Q. Lin and L. J. Ding, "Hybrid instructional design oriented by the cultivation of students' autonomous learning ability," Journal of Multimedia and Network Teaching of China, 2019.

[6] X. L. Ye, "Application of mixed teaching in mental health education for higher vocational students," Journal of Inner Mongolia Normal University, 2018, vol. 8, pp. 86-90.

[7] F. Yu and Q. Rose, "Developing and implementing college students 'entrepreneurship course with mixed teaching method and its enlightenment-taking the entrepreneurship course of North Umbria University as an example," Journal of Linyi University, 2018, vol. 04, pp. 7-13.
[8] Y. C.Liao, "Research on the application of mixed teaching model in English classroom," Collection of Scientific Research Achievements of Teachers 'Teaching Ability Development, 2018, vol. 3.

[9] W. Y. Jiang and F. H. Yang, "Design and application of "SPOC + classroom" hybrid teaching based on erya platform," Computer Education, 2017, vol. 12, pp. 90-93, 97.

[10] Application of Hangwen He Jie Mao Navy's "Problem-driven" teaching method in the interdisciplinary course of "transportation economics", Teaching in Chinese Universities, no. 09, 2012.

[11] H. M. Pei and X. Wang, "Application of primitive problem-driven teaching method in higher mathematics teaching," Higher Education Online, no. 892 , p. 155.

[12] J. Zhu and M. Sha, "Problem-driven teaching model for software testing course, University of China," no. 10, 2018, pp. 32-36.

[13] J. Huang and X. F. Jia, "Discovery and transformation: Problem-driven teaching practice exploration of urban residential".

[14] Course, Southern Architecture, 2017.

[15] F. Mei et al., "Application and research of problem-driven teaching method in numerical analysis," Science and Technology Perspective of Longyuan Journal Network, 2014, vol. 13.

Copyright (C) 2019 by the authors. This is an open access article distributed under the Creative Commons Attribution License which permits unrestricted use, distribution, and reproduction in any medium, provided the original work is properly cited (CC BY 4.0).

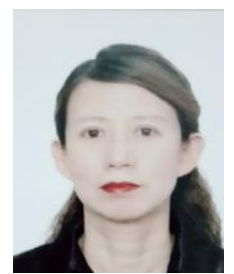

Yang Yanbing is a $\mathrm{Ph} . \mathrm{D}$. in transportation planning and management in 2009. She is a professor. In 2004 she was authorized by the State Education Commission to study abroad in France, majoring in game theory.

She is a teacher of the Faculty of Science of Dalian Maritime University. She has published more than 40 academic papers in journals and conferences at home and abroad, many of which have been searched by EI, ISTP, ISSHP and SCI. She is the author of "Evolution of Cooperation with Moore Neighborhood and Self-Playing Rule" and other papers.

She has presided over and participated in more than 30 projects of the National Natural Science Foundation, provincial and municipal projects, horizontal projects and school education reform projects.

Professor Yang was awarded one award for academic achievements of Natural Science in Liaoning Province, one award for teaching achievements of general higher education in Liaoning Province and four awards for excellent teaching at the school level of Dalian Maritime University. 